\title{
Rheumatology and Orthopedic Medicine
}

\section{Review Article}

\section{Boron action in bone health}

\author{
Dessordi $\mathrm{R}^{* 1}$, and Navarro MA ${ }^{1}$ \\ ${ }^{1}$ Department of Food and Nutrition, Faculty of Pharmaceutical Sciences, State University of São Paulo - UNESP, Araraquara, Brazil
}

\begin{abstract}
The function of boron in humans and animals is the focus of much research, especially in bone health. Boron is a trace element capable of providing proper bone growth and development, and positively influences minerals such as calcium, phosphorus and magnesium and act in synergy with vitamin D. Chemical structure allows boron form complexes with organic molecules that have adjacent hydroxyl groups in cis position. This feature permits the formation of steroid hormones and hence its supplementation in postmenopausal women can be beneficial. Also, the studies suggest the benefit of boron supplementation for bone health. Scientific evidence shows that deprivation can lead to abnormal bone development, loss of bone strength and impaired brain function. Therefore, the aim of this study was to review the primary studies that guide the function and importance of boron to the human and animal body. The study compiled from a survey of articles using the Pubmed database. From the investigation, data verified the importance of boron for growth and maintenance of bone health.
\end{abstract}

\section{Introduction}

Boron (B) is a mineral that is the focus of many studies for establishing a role for the human organism, especially its influence on bone metabolism. Its essentiality for plants well accepted, but for human's study suggested their influence on the metabolism of nutrients such as calcium, magnesium and vitamin $\mathrm{D}$, proper bone growth, the formation of steroid hormones and activity of some enzymes [1,2].

Studies indicate that boron is a bioactive food component that is beneficial, if not essential, for the maintenance of health. Deprivation can lead to changes in brain function and impaired strength and bone structure [3].

Based on the literary evidence the aim of this study was to review the primary studies that guide the function and importance of boron to a human and animal body.

A survey of papers discussing the influence of boron on human and animals, evaluating the effects of supplementation, deprivation, and relationship with minerals like calcium, phosphorus, magnesium, and vitamin $\mathrm{D}$ was collected. Review articles that agree with the objective of work were selected. We used the PubMed database to perform the collection of articles. The terms used in the search were: boron diet, and boron, bone and boron, boron functions, boron metabolism.

\section{Boron}

Boron is a trace mineral that proven essential throughout in the lifecycle for organizations across a phylogenetic kingdom. This mineral found in the form of boric acid $\left(\mathrm{H}_{3} \mathrm{BO}_{3}\right)$ at physiological $\mathrm{pH}$, studies show that boron is required for a good bone health, playing a vital role in embryogenesis, bone growth, and immune functions psychomotor [3-5].

The boron atom has three electrons in its outer shell; do not donate protons, but acts as a Lewis acid, accepting hydroxyl ions. Boron binds with various elements, resulting in a tetrahedral or trigonal planar arrangement, having a strong attraction by oxygen resulting in the formation of borates. When the boron is bound to four oxygen atoms, the resulting compound in tetrahedral anion is borate $\left(\mathrm{B}(\mathrm{OH})_{4}\right)^{-6}$.
When binds to three oxygen atoms the resulting compound in the triangular planar arrangement are acid orthoboric $\left(\mathrm{B}(\mathrm{OH})_{3}\right)$ [2].

Boron has a strong tendency to form complexes with organic molecules having adjacent hydroxyl groups that are in the cis configuration. This mineral can interact with important biological substances, including polysaccharides, pyridoxine, riboflavin, dehydroascorbic acid, and pyridine nucleotide. The nicotinamide adenine dinucleotide (NAD+) and nicotinamide adenine dinucleotide phosphate (NADP) ribose contain components that have a strong affinity for boron, and these molecules are active in energy metabolism. Thus, the connection between them and boron may affect some processes of specific metabolic pathways. Therefore, the chemical structure of the mineral allows it to react with many other enzymes and metabolites, may be able to modify the mineral and energy metabolism in human beings and animals $[2,6]$.

\section{Toxicity, deficiency, absorption and excretion}

The boron intoxication is not typical because the excess of this mineral usually excreted in the urine. The biochemical toxicity symptoms are similar to pellagra and include riboflavinuria and riboflavin deficiency with inhibition of dehydrogenase enzymes. Deficiency symptoms include nausea, vomiting, diarrhea, kidney damage, hyponatremia, agitation and fatigue. Moreover, its deficiency in humans, rats and chickens lead to an abnormal bone development, independent of the other stressor affects bone health and causes an increase in the urinary excretion of cálcio2. Studies have shown that boron deprivation affects two organs, the bone and brain and, response

Correspondence to: Dessordi R, Department of Food and Nutrition, Faculty of Pharmaceutical Sciences, State University of São Paulo - UNESP, Araraquara, Brazil, E-mail: re_dessordi@hotmail.com

Key words: boron, bone health, minerals

Received: February 04, 2017; Accepted: February 22, 2017; Published: February 24,2017 
to withdrawal is enhanced when other nutrients that alter the metabolic functions are also impaired, such as magnesium, calcium and vitamin $\mathrm{D}[1,7]$.

Boron is a mineral easily absorbed through the gastrointestinal epithelium, and may reach an absorption rate to about $90 \%$. When enters the body, it is hydrolyzed to boric acid, which is absorbed by enterocytes and transported. Suggested that during transport boron linked to substances containing cis-hydroxyl groups. The mechanism by which boron incorporated remains inconclusive. However, some studies suggest that is by a not induced diffusion process. This mineral mostly excreted in the urine, about $2 \%$ in the feces and the remainder of perspiration and breathing $[2,4]$. The boron concentration in tissues remains constant through a homeostatic mechanism that directly related to renal excretion, and this mechanism allows that high intake of boron does not increase their levels in plasma significantly [6].

\section{Food and recommended sources}

The primary dietary sources of boron are fruits, vegetables, and tubers especially those from dicotyledonous plants. The grasses such as corn, rice and wheat have minor amounts. Dried fruits, nuts and avocados contain between 1 and $4.5 \mathrm{mg}$ of boron/100 g. Fresh fruits, vegetables, and honey, contains between 0.1 to $0.5 \mathrm{mg}$ boron/ $100 \mathrm{~g}$, whereas animal foods provide only 0.01 to $0.06 \mathrm{mg}$ of boron $/ 100 \mathrm{~g}$. Another important source of boron is water, and the content varies according to geographic location $[6,2]$.

According to DRI's (Dietary Reference Intakes), there is no adequate intake values (AI), estimated average requirement (EAR) and recommended dietary allowance (RDA). The only values are the tolerable upper limit (UL) for the age group 19 and $70(20 \mathrm{mg} /$ day of boron) [8]. Recommendations for animals according to AIN-93, is 0.5 $\mathrm{mg} / \mathrm{kg}$ of diet for the growth, reproduction and maintenance [9].

\section{Action in the body and bone}

The boron interest in the animal nutrition began in 1981. Boron plays a regulatory role in the metabolism of various micronutrients such as calcium, phosphorus, aluminum and molybdenum. The micronutrients relation to bone metabolism are magnesium, calcium, phosphorus, boron and vitamin D. Suggested that boron positively influences the metabolism of these nutrients that play a significant role in maintaining bone health. The average consumption of boron evaluated in a population of the United States was about $0.86 \mathrm{mg}$ per day, via ingested food. This mineral can found in tissues and body fluids as a result of a healthy diet, and bones, nails and hair usually have higher boron levels than other tissues [10,11,7].

Studies with chickens supplemented with boron $(3 \mathrm{mg} / \mathrm{kg}$ of diet) suggest that it can affect some aspects of vitamin D metabolism. This action can influence on growth. Subsequent studies with diets containing boron and magnesium in the presence of moderate amounts of vitamin D showed that the animals were able to maintain an adequate rate of growth in magnesium-deficient diet but supplemented with boron, independent of vitamin $\mathrm{D}$ presence. Another issue addressed by this study related to deprivation of boron in the diet of chickens accompanied by moderate amounts of vitamin $\mathrm{D}$ in their composition. Microscopic analyzes performed in this group suggested delaying the calcification of cartilage pieces and also observed a decrease in density of chondrocytes of cell proliferation zone in the deficiency of boron and cholecalciferol. Based on the findings, it is suggested that boron can enhance cell maturation and growth of long bones $[3,12]$.
Evaluating the boron relationship with vitamin D it found that the chickens that received a diet deficient in vitamin $\mathrm{D}$ but supplemented with boron increased the 25-hydroxycholecalciferol and 1,25-dihydroxycholecalciferol concentrations. For proper diet in vitamin $\mathrm{D}$ and low levels of boron, there was an increase in plasma concentrations only 1,25-dihydroxycholecalciferol, suggesting a positive relationship between boron and this vitamin13. These findings are suggesting that boron may play a role in the extent of hydroxylation or a half-life of vitamin D3, based to form complexes with hydroxyl groups into organic compounds ability. Therefore, boron could affect bone metabolism and improving bone strength [2].

The interaction of boron with calcium suggests that boron supplementation led to a reduction in urinary calcium excretion and increased ionized calcium levels in the plasma. Furthermore, there is evidence that calcium supplementation alone is not adequate to prevent bone loss. Studies in pre-and post-menopausal women revealed that boron supplementation was able to increase calcium absorption $[2,14]$.

Studies conducted in animals that received a diet deficient in magnesium, but supplemented with boron had reduced the level of abnormalities caused by magnesium deficiency and increased this mineral in plasma. Also, it observed that pre-and post-menopausal women supplemented with boron had a lower urinary magnesium excretion $[2,14]$.

The boron supplementation was able to increase bone strength in rats. Furthermore, boron supplementation led to an increase in the resistance force of the vertebra in contrast to the deprivation that caused a reduction in the fraction of bone volume, trabecular thickness and greater separation between the trabecular bone $[15,16]$.

Studies demonstrated that boron is an important nutrient for humans. Researchers with men over 50 years and post-menopausal women on hormone therapy that received boron supplementation after boron deprivation show that supplementation was affected copper and magnesium metabolism and energy metabolism of reactive oxygen and nitrogen in humans positively. This study also suggested that the B affects brain function and psychomotor performance [3,7].

Studies in animals have shown that supplementation with boron can improve pain in patients with mild to moderate osteoarthritis. Supplementation with $6 \mathrm{mg}$ boron per day in their chemical form calcium fructoborate the naturally occurring boron complex found in fruits and vegetables has been able to alleviate the symptoms of the disease. After eight weeks of supplementation, $80 \%$ of patients have reduced or eliminated the use of analgesics [17]. Subsequently inflammatory profile was evaluated before supplementation with 3.6 or $12 \mathrm{mg} /$ day, and the results showed a reduction in serum concentration of C-reactive protein, fibrinogen and erythrocyte sedimentation plasma compared to the placebo group [18].

Boron supplementation can also affect circulating insulin concentration because it can reduce the amount of insulin required to maintain blood glucose levels by alterations in NADPH metabolism. Changes in the NADPH metabolism cause alterations in the dynamics cell membrane, promoting insulin secretion [6.2]. In rats in the night fasting, deprivation of boron increased plasma insulin levels, but there was no change in the concentration of glucose. In chickens, boron deprivation caused an increase in peak insulin release by the pancreas [19].

The steroid hormones directly related to the bone and boron may play a significant role in bone health through the formation of 
steroid hormones. Thus, be involved in preventing calcium loss and bone demineralization. The chemistry of this mineral can promote the formation of testosterone and estradiol $17 \beta$ from precursors involving the addition of hydroxyl groups to steroidal rings [2].

In vitro studies with cultures of osteoblastic cells (MC3T3-E1), also demonstrated that boron is beneficial for maintaining and bone formation by stimulating bone mineralization and still increasing levels mRNA related to bone growth as type I collagen and osteocalcin [20].

Although the evidence of in vivo and in vitro studies proving the benefit of boron in bone health, more studies are needed, including human studies, to better understand the mechanisms involved in bone health improvement $[3,21]$.

\section{Conclusion}

The evidence highlights the essential of boron in the normal development of the skeleton, maintenance of bone health throughout life and beneficially influences minerals such as calcium magnesium, and vitamin D. Also, this mineral also plays a significant role in shaping steroid hormones that related to bone health, especially in women after menopause.

\section{Acknowledgements}

The Foundation to Support the Teaching, Research and Assistance -FAEPA of the HCRP-FMRP that funded this study.

\section{References}

1. Gallagher ML. Os Nutrientes e Seu Metabolismo (cap. 03). In: L. Kathleen Mahan, Sylvia Escott-Stump. Alimentos, Nutrição e Dietoterapia, 12 ${ }^{\mathrm{a}}$ ed. Rio de Janeiro: Elsevier, 2010, p. 134.

2. Devirian TA, Volpe SL (2003) The physiological effects of dietary boron. Crit Rev Food Sci Nutr 43: 219-231. [Crossref]

3. Nielsen FH (2014) Update on human health effects of boron. J Trace Elem Med Biol 28: 383-387. [Crossref]

4. Da Silvia AGH, Pires LV.; Cozzolino, S.M.F. Boro (cap. 33). In: Silvia M. Franciscato Cozzolino. Biodisponibilidade de Nutrientes, $4^{\mathrm{a}}$ ed. Barueri: Manole, 2012, p. 814-817.

5. Tash PN, Dogan A, Demirci S, Sahin F (2013) Isolation enhances odontogenic and osteogenic differentiation human tooth germ stem cells (hTGSCs) in vitro. Biol. Trace Elem. Res 153: 419-427.
6. Hunt CD (2012) Dietary Boron: Progress in Establishing Essential Roles in Human Physiology. J Trace Elem Med Biol 26: 157-160. [Crossref]

7. Nielsen FH (2008) Is boron nutritionally relevant? Nutr Rev 66: 183-191. [Crossref]

8. Institute of Medicine - IOM. DRI's - Dietary reference intakes for vitamin a, vitamin $\mathrm{K}$, arsenic, Boron, chromium, copper, iodine, iron, Manganese, Molybdenum, nickel, Silicon, vanadium and zinc. Washington, DC: national academy Press, 2002. Disponível em:

9. Reeves PG, Nielsen FH, George C, Fahey GC (1993) AIN-93 purified diets for laboratory rodents: final report of the american institute of nutrition ad hoc writing committee on the reformulation of the ain-76a rodent diet. $J$ Nutr 123: 1939-1951. [Crossref]

10. Nielsen FH (2000) The emergence of boron as nutritionally important throughout the life cycle. Nutrition 16: 512-514. [Crossref]

11. Gallardo-Williams MT, Maronpot RR, Turner CH, Johnson CS, Harris MW, et al (2003) Effects of boric acid supplementation on bone histomorphometry, metabolism, and biomechanical properties in aged female F-344 rats. Biol Trace Elem Res 93: 155169. [Crossref]

12. Hunt CD (1994) The Biochemical Effects of Physiologic Amounts of Dietary Boron in Animal Nutrition Models. Environ Health Perspect 102 (Suppl. 7) 35-43. [Crossref]

13. Bai Y, Hunt CD (1996) Dietary boron enhance efficacy of cholecalciferol in broiler chicks. J. Trace Elem. Exp. Med 9: 117-32.

14. Palacios C (2006) The role of nutrients in bone health, from A to Z. Crit Rev Food Sci Nutr 46: 621-628. [Crossref]

15. Hakki SS, Dundar N, Kayis SA, Hakki EE, Hamurcu M, et al. (2013) Boron enhances strength and alters mineral composition of bone in rab- bits fed a high energy diet. $J$ Trace Elem Med Biol 27: 148-153. [Crossref]

16. Ying X, Cheng S, Wang W, Lin Z, Chen Q, et al. (2011) Effect of boron on osteogenic differentiation of human bone marrow stromal cells. Biol Trace Elem Res 44: 306-315. [Crossref]

17. Miljkovic D, Scorei RI, CimpoiaÅŸu VM, Scorei ID (2009) Calcium fructoborate plant-based dietary boron for human nutrition. J Diet Suppl 6: 211-226. [Crossref]

18. Scorei R, Mitrut P, Petrisor I, Scorei I (2011) A double-blind, placebo-controlled pilotstudy to evaluate the effect of calcium fructoborate on systemic inflammationand dyslipidemia markers for middle-aged people with primary osteoarthritis. Biol Trace Elem Res 144:253-63. [Crossref]

19. Bakken NA, Hunt CD (2003) Dietary boron decrease peak pancreatic in situ insulin release in chicks and plasm insulin concentration in rats regardless of vitamin D or magnesium status. J Nutr 133: 3516-22. [Crossref]

20. Hakki SS, Bozkurt BS, Hakki EE (2010) Boron regulates mineralized tissue-associated proteins in osteoblasts (MC3T3-E1). J Trace Elem Med Biol 24: 243-250. [Crossref]

21. Nielsen FH (1998) The justification for providing dietary guidance for the nutritional intake of boron. Biol Trace Elem Res 66: 319-330. [Crossref]

Copyright: (C2017 Dessordi R. This is an open-access article distributed under the terms of the Creative Commons Attribution License, which permits unrestricted use, distribution, and reproduction in any medium, provided the original author and source are credited. 